\title{
Adecuación de la Jurisdicción Penal Militar Chilena de Tiempo de Paz a los Estándares Internacionales de Derechos Humanos
}

Este comentario, junto a los documentos que analiza, está disponible en www.anuariocdh.uchile.cl

\author{
Jorge Mera Figueroa*
}

\begin{abstract}
$\mathcal{L}$ a Corte Interamericana de Derechos Humanos, en su sentencia del día 22 de noviembre de 2005 recaída en el caso Palamara Iribarne c. Chile, dispuso que "[e]/ Estado debe adecuar, en un plazo razonable, el ordenamiento jurídico interno a los estándares internacionales sobre jurisdicción penal militar, de forma tal que en el caso de que considere necesaria la existencia de una jurisdicción penal militar, ésta debe limitarse solamente al conocimiento de delitos de función cometidos por militares en servicio activo. Por lo tanto, el Estado debe establecer, a través de su legislación, límites a la competencia material y personal de los tribunales militares, de forma tal que en ninguna circunstancia un civil se vea sometido a la jurisdicción de los tribunales penales militares, en los términos de los párrafos 256 y 257 de la presente Sentencia" (XIII, Puntos resolutivos, 14). En el párrafo 257 citado se establece que "en el ámbito de la jurisdicción penal militar, los miembros de los tribunales deben revestir las garantías de competencia, imparcialidad e independencia indicadas en los párrafos 120 a 161 de la presente Sentencia. Asimismo, el Estado debe garantizar el debido proceso en la jurisdicción penal militar y la protección judicial respecto de las actuaciones de las autoridades militares, tal como se ha señalado en los párrafos 162 a 189 de este fallo".
\end{abstract}

El fallo de la Corte, en concordancia con la reciente doctrina nacional sobre la materia ${ }^{1}$, identifica claramente las graves falencias que presenta nuestra justicia militar desde la perspectiva del Derecho Internacional de los Derechos Humanos, y que pueden resumirse de la siguiente manera: (a) ámbito desmedido de la competencia de los tribunales militares que permite el juzgamiento de civiles y militares por delitos comunes, en circunstancias de que debiera limitarse exclusivamente al conocimiento de los delitos propiamente castrenses cometidos por militares; (b) estructura y organización de los tribunales militares que compromete el derecho de los imputados a ser juzgados por un tribunal independiente ${ }^{2}$ e imparcial $^{3} ;$ y, (c) procedimiento escrito, de carácter inquisitivo, estructuralmente contrario a las garantías del debido proceso ${ }^{4}$.

Profesor de Derecho Penal. Miembro del Centro de Investigaciones Jurídicas, Facultad de Derecho, Universidad Diego Portales.

1 Ver, entre otros, "Justicia Militar y Estado de Derecho", Jorge Mera (editor), en Cuadernos de Análisis Jurídico, serie Seminarios, N 40, Escuela de Derecho, Universidad Diego Portales, 1998.

2 La falta de independencia de los tribunales militares chilenos ha sido observada desde antiguo. En su discurso de inauguración del año judicial 1989, el Presidente de la Corte Suprema denunciaba que "los principios fundamentales que deben regir la organización de los tribunales de justicia (...) tienen una muy precaria vigencia en los tribunales castrenses. En efecto, siendo sus magistrados personal de las Fuerzas Armadas, los que de partida están sometidos a reglamentos de disciplina muy importantes, desaparece la garantía de la inamovilidad, la que es básica y fundamental en relación con la independencia del juez".

3 El derecho del imputado a ser juzgado por un tribunal imparcial resulta infringido doblemente en nuestro sistema de administración de justicia militar, puesto que: (1) los tribunales militares tienen competencia para conocer de delitos cometidos por civiles en contra de bienes jurídicos de carácter castrense o de miembros, unidades o reparticiones de las FF.AA. o de Carabineros, y; (2) son competentes para conocer de los delitos comunes perpetrados por militares o carabineros en contra de los civiles cometidos por militares o carabineros en acto del servicio militar o en recintos militares o policiales.

4 La reforma estructural del procedimiento penal, de corte acusatorio y que entró en vigencia gradualmente a partir de diciembre de 2000, dejó incólume el procedimiento penal militar de carácter inquisitivo. 
Por su parte, el Comité de Derechos Humanos de las Naciones Unidas, en su Examen del Informe presentado por el Estado chileno con arreglo al art. 40 del Pacto (89 período de sesiones), "observa con preocupación la persistencia de la jurisdicción de los tribunales militares chilenos para procesar a civiles por cuestiones civiles, que no es compatible con el artículo 14 del Pacto", y recomienda que "El Estado Parte debería agilizar la adopción de la ley que modifique el Código de Justicia Militar, limitando la jurisdicción de los tribunales militares únicamente al enjuiciamiento de personal militar acusado de delitos de carácter militar exclusivamente; verificando que esta ley no contenga ningún precepto que pueda permitir violaciones de los derechos establecidos en el Pacto"(párr.12).

Los problemas que plantea la jurisdicción penal militar chilena en tiempo de paz $z^{5}$ desde la perspectiva del derecho internacional de los derechos humanos, son básicamente dos: (1) ¿Se justifica dicha jurisdicción especial? ¿ $\mathrm{O}$, por el contrario, los delitos militares cometidos por militares en servicio activo debieran ser del conocimiento de los tribunales civiles ordinarios, como ocurre en otros sistemas jurídicos? ${ }^{6}$ (2) Admitida la necesidad de la existencia de esta jurisdicción especial, es necesario precisar las condiciones para su legitimación, como son el juzgamiento sólo de delitos militares cometidos por militares, efectuado por tribunales independientes e imparciales y con reglas que respeten las garantías del debido proceso.

La definición de la necesidad de tener una jurisdicción especial habitualmente se presenta como una opción legítima de los Estados, sujeta a su estimación político-jurídica. Más allá del debate en torno de las razones justificatorias tradicionalmente invocadas a favor de esta jurisdicción penal especial ${ }^{7}$, desde el punto de vista estricto de las garantías fundamentales que integran el debido proceso, la sola existencia de dicha jurisdicción resulta cuestionable, incluso en el supuesto ideal de una estructura y organización adecuadas y de un procedimiento penal que cumpliera con dichas garantías. Aun en tal evento, el conflicto que debe resolver el tribunal especial se deriva del hecho de atentar un militar en contra del deber de prestar el servicio militar o en contra de los deberes militares que le corresponden, ya sea como superior o subordinado. La contraposición de intereses, propia de todo proceso penal, se presenta aquí, por una parte, en el interés del Estado en que se persigan y castiguen las diversas infracciones de los deberes militares tipificadas como delitos castrenses, y por la otra, en el interés de los imputados (militares en servicio activo, en el supuesto examinado) en que se respeten sus garantías penales. Es razonable pensar que estas últimas estarán mejor protegidas si el juzgamiento lo llevan a cabo tribunales civiles ordinarios, que gozan de total independencia y absoluta imparcialidad para juzgar dicho conflicto, y no tribunales militares, cuyos miembros pueden sentirse comprensible y acaso inconscientemente inclinados a favorecer uno de los intereses en pugna (a saber, el militar), en desmedro del otro (las garantías del militar imputado).

Descartada la supresión de la jurisdicción penal militar, la segunda alternativa es el establecimiento de un fuero militar restringido al conocimiento de los delitos propiamente castrenses cometidos por militares, tal como se señala en las decisiones internacionales citadas. Los problemas que se plantean en relación a las condiciones de su legitimación, básicamente son tres: (a) que la competencia de los tribunales castrenses se limite efectivamente al conocimiento de delitos propiamente militares cometidos por militares (¿qué es lo que los tribunales militares deben juzgar?); (b) que

5 Dados los objetivos del presente artículo, me ocuparé sólo de este aspecto.

6 Países con gran tradición militar, como Alemania y Francia, han suprimido la jurisdicción penal militar en tiempo de paz, sin que esta circunstancia haya mermado la eficacia de sus Fuerzas Armadas.

7 Básicamente son dos: (a) la especialidad y complejidad de los delitos militares y, (b) la necesidad de preservar la disciplina. 
la estructura y organización de los tribunales militares garanticen el derecho de los imputados a ser juzgados por un tribunal independiente e imparcial ${ }^{8}$, y (c) que el procedimiento penal militar cumpla con las exigencias del debido proceso. Estos dos últimos aspectos guardan relación con el cómo debe realizarse dicho juzgamiento.

¿Qué es lo que los tribunales militares deben juzgar? Esta es la pregunta básica, toda vez que la respuesta a ella es lo que justifica, dentro de la lógica y el sentido de dicho modelo de fuero restringido, su propia existencia. Una vez que se ha determinado en forma precisa el concepto de delito militar, cobra importancia el cómo debe procederse al juzgamiento de los delitos militares.

Un punto a considerar es el relativo a la necesidad de contemplar delitos militares. ¿Se justifica un Derecho Penal Militar? Me parece, fuera de dudas, que sí. Existen, en efecto, bienes jurídicos de carácter militar de la mayor relevancia para toda la sociedad que sólo pueden ser afectados por los miembros de las Fuerzas Armadas y que requieren de protección penal, siendo insuficientes las sanciones administrativas o disciplinarias. Los más graves atentados en contra de la eficacia de los institutos armados -órganos técnicos de combate especializados en la protección de la seguridad exterior del Estado- cometidos por militares tienen la suficiente relevancia para merecer sanción penal, siendo lógico que integren un catálogo especial de delitos: los delitos militares. Por otra parte, la especialidad de estas infracciones, derivada tanto de la naturaleza militar del bien jurídico protegido como de la calidad de los infractores (uniformados que infringen sus deberes militares), justifica su tipificación separada9 .

Actualmente existe un consenso generalizado en la doctrina en el sentido de que los delitos militares son delitos especiales propios que se integran con dos elementos copulativos: (1) la naturaleza militar del bien jurídico $\operatorname{protegido}^{10}, \mathrm{y}$; (2) la calidad militar del sujeto activo que infringe sus deberes militares.

Para que un delito sea militar no basta con la afectación de un bien jurídico de carácter militar. Los civiles también pueden afectarlo (Vg. apropiación de material de guerra o falsificación de documentos militares), sin que esto configure una infracción a un delito militar. La infracción de un deber específicamente militar es un elemento consustancial de los delitos militares: "...el delito militar ha menester tanto de la calidad del autor como del carácter castrense de los bienes o intereses protegidos. Si el delito militar entraña una violación al deber militar, no nos parece dudoso que la ley penal militar sólo puede dirigir su mandato, y exigir el cumplimiento del deber militar, a quien ostente ese carácter. Afirmar que una persona sin estado militar puede cometer un delito militar, importa tanto como admitir que un civil pueda violar mandatos dirigidos a los militares"11.

8 En la sentencia "Palamara Iribarne c. Chile", "La Corte estima que la estructura orgánica y composición de los tribunales militares (chilenos) (...) supone que, en general, sus integrantes sean militares en servicio activo, estén subordinados jerárquicamente a los superiores a través de la cadena de mando, su nombramiento no depende de su competencia profesional e idoneidad para ejercer las funciones judiciales, no cuenten con garantías suficientes de inamovilidad y no posean una formación jurídica exigible para desempeñar el cargo de juez o de fiscales. Todo conlleva a que dichos tribunales carezcan de independencia e imparcialidad" (párr. 155).

9 Países como Francia y Alemania, que han abolido la jurisdicción penal militar en tiempo de paz, poseen códigos o leyes de justicia militar que siguen contemplando un catálogo de delitos militares, de los que conoce la justicia ordinaria.

10 El bien jurídico protegido en los delitos militares es la eficacia de las instituciones armadas como organismos de combate técnico-profesionales especializados en la protección de la seguridad exterior del Estado. Por esta razón, los miembros de Carabineros de Chile -institución de carácter policial que sólo tiene la función de resguardar la seguridad y el orden público y dar eficacia al derecho- debieran quedar excluidos del Derecho Penal Militar.

11 Zaffaroni y Cavallero, Derecho Penal Militar, Ariel, Buenos Aires, 1980, p. 28. 
Los deberes militares que emanan del servicio militar son básicamente los de la disciplina y la obediencia. La tipificación del delito debiera radicarse en la infracción del deber militar, distinguiéndose por tanto los delitos que atentan en contra del deber de prestar el servicio militar (abandono de servicio, abandono de destino o residencia, deserción, automutilación, evasión del servicio militar), delitos de los superiores (maltratos, trato degradante, amenazas, coacciones y ofensas a los inferiores, usurpación y abuso del mando y del poder disciplinario, omisión de mantener la disciplina, denegación de auxilio a las fuerzas combatientes) y delitos de los subordinados (motín, desobediencia, maltratos, amenazas, coacciones y ofensas a superiores).

La correcta determinación de los delitos militares y una competencia de los tribunales castrenses restringida al conocimiento de esta clase de infracciones excluye no sólo el juzgamiento de civiles por los tribunales militares, sino también el juzgamiento de militares por delitos "comunes"12, pues el hecho punible no constituye una infracción de deber militar que le corresponda a aquéllos en tanto miembros de las Fuerzas Armadas ${ }^{13}$.

Nuestro Código de Justicia Militar (CJM) ofrece un concepto puramente formal de delito militar, que no alude a la naturaleza de la infracción. El artículo 5, № 1 define delitos militares para los efectos de la jurisdicción militar como "los contemplados en este Código". Como lo señala el más importante comentarista de dicho cuerpo legal, "En nuestro país, de acuerdo con nuestra legislación positiva, el delito militar tiene un carácter amplísimo: se consideran delitos militares no sólo ciertos delitos que pueden ser cometidos por civiles (hurtos de especies militares, ofensas y violencia a carabineros), sino que aun algunos que no lesionan intereses institucionales (infracciones a la Ley de Navegación Aérea)"14.

Con todo, el CJM asume que se trata de una ficción. En el artículo 215 establece que "Los delitos militares serán sancionados con penas comunes o con penas militares, según la naturaleza del delito". La referencia que se hace a la naturaleza del delito alude a la índole común o militar de la infracción, de acuerdo con la clase de penas asignadas en uno y otro caso, siendo esta la manera de reconocer los delitos propiamente militares en el CJM. Es así como los delitos de los Títulos II (De la traición, del espionaje y demás delitos contra la soberanía y seguridad exterior del Estado), III (Delitos contra el Derecho Internacional), IV (Delitos contra la seguridad interior del Estado), VIII (Delitos contra los intereses del Ejército ${ }^{15}$ ), IX (Delitos contra la propiedad) y X (Delitos de falsedad) del Libro III, son castigados con penas comunes (con la excepción del artículo 245 del Título III), por lo que, de acuerdo con el predicamento del propio CJM, no son delitos propiamente militares. Todos ellos debieran ser eliminados en una futura reforma, puesto que se trata de delitos comunes, susceptibles de ser cometidos por civiles.

El gobierno de Chile presentó un Proyecto de Ley (Boletín № 5.159-07), que persigue la modificación de la competencia de los tribunales militares y la supresión de la pena de muerte. Dicho

12 "En un Estado democrático de derecho la jurisdicción penal militar ha de tener un alcance restrictivo y excepcional y estar encaminada a la protección de intereses jurídicos especiales (...) Por ello, sólo se debe juzgar a militares por la comisión de delitos o faltas que por su propia naturaleza atenten contra bienes jurídicos propios del orden militar". Corte Interamericana, caso Palamara Iribarne c. Chile, párr. 124.

13 Una investigación empírica (1990-1996) evidenció que prácticamente el 70\% de las causas tramitadas en los tribunales militares son seguidas en contra de civiles, principalmente por el delito de maltrato de obra a carabineros, el cual se presenta habitualmente con ocasión del control por parte de la policía de protestas y manifestaciones ciudadanas; sólo el $8,81 \%$ de los militares fueron imputados por delitos propiamente militares. "La Justicia Militar, una mirada en cifras", en Justicia Militar y Estado de Derecho, op. cit., p. 199 y ss.

14 Renato Astrosa H., Comentarios al Código de Justicia Militar, Ed. Jurídica de Chile, p. 29.

15 Este título trata casos de delitos y penas comunes que pueden ser cometidos tanto por civiles como por militares (por ejemplo, daños y estragos causados a cuarteles), o bien sólo por civiles (como es el caso del suministro a las tropas de víveres averiados o adulterados). 
Proyecto no resulta consistente con la resolución de la Corte Interamericana, ni con la recomendación del Comité de Derechos Humanos de la ONU. Por una parte, mantiene un concepto formal de delito militar que permite el juzgamiento de delitos comunes cometidos por militares e incluso el de civiles. Por otra, no se refiere en absoluto a la estructura y organización de los tribunales militares, ni al procedimiento penal contemplado en el Código de Justicia Militar, los cuales, como detalladamente lo consigna el fallo de la Corte Interamericana, infringen en múltiples aspectos las garantías del debido proceso consagradas en la Convención Americana sobre Derechos Humanos $(\mathrm{CADH})^{16}$.

En lo que dice relación con el primer aspecto, el nuevo artículo 3 establece que "Los Tribunales Militares de la República tienen jurisdicción sobre los militares, para juzgar los asuntos de la jurisdicción militar que sobrevengan en el territorio nacional, sin perjuicio de las excepciones establecidas en este Código". Se estipula como principio general que la competencia de los tribunales militares se limite al juzgamiento de militares, pero a renglón seguido se agrega que eso es "sin perjuicio de las excepciones establecidas en este Código", dejando abierta la posibilidad del juzgamiento de civiles, lo que plantea expresamente el mismo Proyecto.

En el mismo sentido, el nuevo artículo 5 propuesto mantiene un concepto formal de delito militar, al establecer que "[l]os tribunales militares son competentes para conocer: $1^{\circ}$ De las causas por delitos militares, entendiéndose por tales delitos los contemplados en este Código, cuando sean cometidos por militares $^{\prime \prime 17}$. Ya se dijo que la mayoría de los Títulos del Libro III del CJM contemplan delitos comunes, que no dejan de serlo por el hecho de que se cometan por militares. El mismo artículo en el inc. 2 del $N^{\circ} 1$, confiere competencia a los tribunales militares para juzgar a civiles, indicando que "[t]endrán también competencia para conocer en todos los casos de los delitos establecidos en los artículos 416, 416 bis, 416 ter y 417 de este Código". Estos son los delitos de amenazas, lesiones y homicidio a carabineros en su calidad de tales, que en caso de ser cometidos por civiles serían de conocimiento de los tribunales militares ${ }^{18}$. Además, el artículo $5 \mathrm{~N}^{\circ} 6$ le otorga competencia a los tribunales para conocer "[d]e las infracciones contempladas en el Código Aeronáutico, sean cometidas por civiles o militares". Finalmente, de acuerdo con el proyecto examinado, los tribunales militares serían competentes para conocer " $[d]$ e las causas por delitos comunes cometidos por militares en el cumplimiento de una orden o en acto de servicio o en recintos militares" (artículo 5, No 4).

El Proyecto del Ejecutivo está lejos de cumplir con la resolución de la Corte Interamericana, la cual estimó que en caso de que se considere necesaria la existencia de una jurisdicción penal militar, ésta debe limitarse solamente al conocimiento de delitos de función cometidos por militares en servicio activo. La mayoría de los delitos a los que el Proyecto del Ejecutivo considera delitos militares (los contemplados en el CJM) no lo son, y no califican, desde luego, como delitos de

\footnotetext{
16 El Estado chileno, desde la recuperación de la democracia a la fecha, ha hecho muy poco para adecuar la jurisdicción penal militar a los estándares internacionales sobre derechos humanos. Aparte de la sustitución de la pena de muerte por el presidio perpetuo en numerosos casos y de la inamovilidad por tres años para los miembros militares de las Cortes Marciales, la modificación más importante fue introducida por la Ley 19.047, que excluyó del conocimiento de los tribunales militares: (a) los delitos terroristas cuando el afectado fuere un miembro de las Fuerzas Armadas o de Carabineros y (b) los delitos de amenazas, ofensas o injurias a las Fuerzas Armadas o a Carabineros, o a sus unidades, reparticiones o miembros, cuando estos delitos fueren cometidos por civiles. En el Proyecto de Ley del Ejecutivo (Boletín $\mathrm{N}^{\circ}$ 5.159-07) se restablece la competencia de los tribunales militares para conocer de las amenazas a los integrantes de Carabineros de Chile, con conocimiento de su calidad de miembros de esa institución, o a las unidades o reparticiones de dicha policía uniformada, sean aquellas perpetradas por militares o civiles.

17 Énfasis añadido.

18 Esto es de especial gravedad, en atención a la frecuencia y relevancia social de estos delitos en el contexto de manifestaciones públicas.
} 
función. Tampoco corresponden a esta categoría los delitos comunes cometidos por militares. Además, no se modifica la estructura y organización de los tribunales militares que en opinión de la Corte Interamericana resultan contradictorias con el derecho de los imputados a ser juzgados por un tribunal competente, independiente e imparcial, ni el procedimiento inquisitivo vigente, que según el mismo tribunal internacional viola las garantías del debido proceso

En cuanto al juzgamiento de civiles, que el proyecto posibilita, la contradicción con la resolución de la Corte Interamericana es clara, puesto que ésta señaló que "[e]/ Estado debe establecer, a través de su legislación, límites a la competencia material y personal de los tribunales militares, de forma tal que en ninguna circunstancia un civil se vea sometido a la jurisdicción de los tribunales militares" (párr. 256).

\section{Conclusiones}

(a). La normativa jurídica del Estado chileno sobre la jurisdicción penal militar de tiempo de paz contradice los estándares internacionales de derechos humanos en aspectos tan relevantes como el derecho a ser oído por un juez o tribunal competente, independiente e imparcial, conforme con un procedimiento que asegure las garantías del debido proceso.

(b). El Proyecto de Ley presentado por el gobierno resulta insatisfactorio por cuanto no cumple con los estándares internacionales de derechos humanos sobre la materia. La adecuación del sistema de administración de justicia penal militar en tiempo de paz a los estándares internacionales de derechos humanos requiere:

- Idealmente, su supresión. Esto, porque aun cuando la jurisdicción penal militar se limitara al conocimiento de los delitos propiamente castrenses cometidos por militares, de todas formas resultaría afectado el derecho de los imputados a ser juzgados por un tribunal imparcial.

- En caso de mantenerse esta jurisdicción especial debiera reformarse integralmente el sistema de administración de justicia penal militar, para ponerlo a tono con: (i) la evolución y desarrollo que han experimentado desde la promulgación del CJM chileno (1925) a la fecha, el derecho internacional de los derechos humanos y la propia concepción y exigencias de la democracia y del estado de derecho; (ii) el desarrollo de las garantías penales sustantivas y procesales penales, de aplicación universal, en caso de cualquier imputación penal, incluidas las relativas a los delitos militares, y; (iii) el progreso histórico del propio Derecho Penal Militar, que se ha traducido en la promulgación, durante la segunda mitad del siglo XX, de nuevos códigos de justicia militar en muchos países.

- Restringirse la competencia de los tribunales militares al conocimiento de los delitos estrictamente militares cometidos por militares en servicio activo que infringen sus específicos deberes castrenses, limitándose el ejercicio del ius puniendi al pleno respeto de las garantías penales propias de un estado democrático de derecho ${ }^{19}$. Esta restricción debiera establecerse, además, en la Constitución, pues si tiene solo consagración legal otra ley del mismo rango podría atribuirle competencia a los tribunales militares para conocer de delitos comunes cometidos por militares o para juzgar a civiles.

19 Especialmente los principios de legalidad, lesividad, culpabilidad, proporcionalidad y prohibición de tratos crueles, inhumanos o degradantes. Debe tenerse presente que la "especialidad" del Derecho Penal Militar radica en su Parte Especial y no en su Parte General. Por lo tanto deben regir para los imputados por delitos castrenses las mismas garantías establecidas para todas las personas, en la Constitución, en los instrumentos internacionales de derechos humanos y en la Parte General de los Códigos Penales. 
- La tipificación de los delitos militares debe realizarse teniendo en consideración su correcto alcance jurídico penal, de acuerdo con la naturaleza de los deberes militares específicos quebrantados. Una reforma del Derecho Penal Militar chileno requiere una completa revisión de nuestro Código de Justicia Militar, con miras a: (i) eliminar los delitos que no constituyen auténticos delitos militares, como ocurre con los previstos en los Títulos II, III, IV, VIII, IX y X del Libro III del CJM, susceptibles todos ellos de cometerse por civiles, por lo que no representan la infracción de un deber militar específico; (ii) reformular -tanto en lo relativo a la tipificación como al castigo- los auténticos delitos militares contemplados en los Títulos V, VI y VII del CJM, superando el casuismo de su actual regulación, sus errores dogmáticos y político-criminales, así como la desproporción de las penas; (iii) incorporar nuevas figuras delictivas que parecen necesarias para proteger apropiadamente la eficacia de las FF.AA al servicio de protección de la seguridad exterior, particularmente lo relativo a infracciones graves de los deberes de los superiores relativas al abuso o exceso de las facultades de mando y del poder disciplinario, y a la promoción o tolerancia del maltrato o trato degradante inferido por los subordinados a otros soldados; (iv) trazar una clara delimitación entre la responsabilidad penal y la disciplinaria, toda vez que no cualquier infracción de los deberes militares debe constituir un delito militar en un derecho penal presidido por el principio de última ratio.

- La jurisdicción penal militar debiera "judicializarse" de modo de asegurar el derecho de los imputados a ser juzgados por un tribunal independiente e imparcial ${ }^{20}$.

- Finalmente, debiera establecerse un procedimiento penal de corte acusatorio, consistente con las garantías del debido proceso consagradas en los tratados internacionales de derechos humanos, de carácter público y oral, en orden de asegurar la presunción de inocencia, el derecho a la defensa, la inmediación y la concentración.

20 La justicia militar debiera incorporar las figuras del juez de garantía y del tribunal oral militar, creando al interior de las FF.AA. una carrera judicial militar de jueces letrados sin subordinación al mando militar, que gocen de autonomía funcional y tengan asegurada la inamovilidad en sus cargos, para asegurar el cumplimiento de las garantías de la independencia (interna y externa) y de la imparcialidad (tanto objetiva como subjetiva). 